\title{
Incremental Conductance based Maximum Power Point tracking on a PV System
}

\author{
Subhash Sharma \\ M.Tech.(Student) \\ Dept. of Electrical Engg. \\ YMCA University
}

\author{
Pooja Khurana \\ Assistant Professor \\ Faculty of Engg.\& Tech. \\ Manav Rachna International \\ Institute of Research and \\ Studies
}

\author{
Romisha Arora \\ Assistant Professor \\ Faculty of Engg.\& Tech. \\ Manav Rachna International \\ Institute of Research and \\ Studies
}

\begin{abstract}
This paper proposed the incremental conductance controller with MPPT by means of boost converter to retain the stable output power of the load at the greatest point under two conditions (i) at unpredictable irradiances, and (ii) stable temperatures and at unpredictable temperatures \& stable irradiances. This paper presents the detail analysis of Maximum power point tracking on a PV system by using INC method. MPPT controller is connected with PV system so that it can extract the maximum power available from the PV system. There are various MPPT controllers are available such as P\&O method, Fuzzy based MPPT controller, INC method etc. In this, flowchart and control algorithm of INC method are discussed. PV system is connected with boost converter to boost its output voltage and the maximum power is tracked from PV system by use of controller, further the boost converter is connected to Inverter and then to the grid.
\end{abstract}

\section{Keywords}

MPPT control, P\&O method, Fuzzy based MPPT controller, INC method, PV array characteristics.

\section{INTRODUCTION}

At present, the demand of Power is rising day by day due to enlarged population and fossil fuel supply viz. petroleum, Coal, and natural gas are going to exhaust, in a few years. The rate of electrical energy consumption is increasing and fuel supply is depleting leading to energy scarcity. Therefore, it is power crisis. Consequently renewable and alternative resources of energy need to be developed to fulfil the requirement of electrical energy. Energy abundance and therefore the property so grid connected electrical phenomenon system is wide used, though alternative energy is offered copiously and freed from price, the value of the electrical phenomenon cells is incredibly high. Thus the initial investment on alternative energy is terribly high. The electrical phenomenon (PV) energy result may be thought of a necessary property resource due to star effulgent the essential component of a PV system is that the cell that converts the star irradiance into DC. Grid interconnection of PV system needs associate degree economical device to device the low DC voltage into AC. PV panels is used either on grid-line or off-grid line. PV panels supply local loads in off-grid line. In on-grid connected applications, the PV system delivers power to local loads as well as to utility grid. Here, the PV system is entitled "grid-connected PV system."

Pv system are now a day's engaged with MPPT controller.The objective of a MPPT technique is to track the Vmpp at the every value of the irradiance and the so the maximum power output Pmpp can be injected into a power system grid. There are several temperature MPPT techniques available to achieve this namely, perturb and observe technique, incremental conductance method, partial short circuit current or open circuit voltage etc.

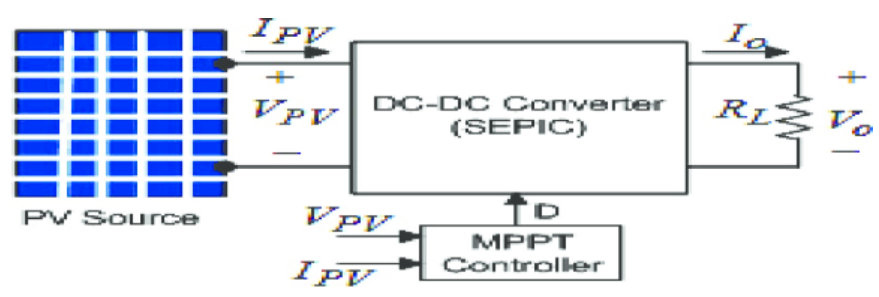

Fig. 1: Diagram of MPPT controller connected with PV source

\section{MPPT Algorithm Technique}

(a) Constant Voltage Method: The Constant Voltage method is the straightforward MPPT algorithm scheme. The working point of the solar PV panel is, every nth step, set aside close to the MPP with modifying panel voltage and corresponding it to a preset position voltage $V_{\text {Ref }}$ the same to the $V_{\text {mpp }}$ of the feature solar module or an additional pre-evaluated greatest voltage assessment. The Constant voltage scheme supposes that the temperature and insulation disparity on the array are irrelevant on the $V_{m p p}$, and that the steady mention voltage $V_{R e f}$ is an enough estimate of the valid MPP. Thus, the working point is not at all accurately at the MPP and diverse data have to be adopted for abnormal ecological sections. The $\mathrm{CV}$ technique needs the dimension of the solar panel voltage $V_{p v}$ to set the duty-cycle $\mathrm{D}$ of the converter. It is essential to examine that while the solar panel has small irradience setting, the $\mathrm{CV}$ procedure is, normally, further efficient than also the IC technique or P \& O technique.

(b) Short-Current Pulse Method: This technique gives a pre-set current $I_{R e f}$ to the power converter controller to get MPP. Actuality, the most favorable working current for highest power output is relative to the short-circuit current $I_{S C}$ in different setting of irradiance stage $\mathrm{S}$ as given below: $I_{R e f}(\mathrm{~s})=K_{p}$ $I_{S C}$ (s) Where $K_{p}$ is proportionality constant. Control algorithm of this technique needs the dimension of the current $I_{S C}$. To get this size, a switch (static) is put in parallel with the solar panel to generate the short- 
circuit situation. While $V_{p v}=0$ no power is delivered via the solar system and no energy is produced therefore. The Short-circuit process needs the measurement of the PV panel current $I_{p v}$ to put up the duty-cycle of the converter.

(c) Open Voltage Method: The Open Voltage technique is on the basis of the study that the voltage $V_{m p p}$ is forever secure to a predetermined fraction of the open-circuit voltage $V_{O C}$ solar insulation level and temperature change the point of the MPP in a $2 \%$ acceptance band. This technique uses $76 \%$ of $V_{O C}$ as reference value $\left(V_{R e f}\right)$.This control algorithm of open voltage method needs capacity of voltage $V_{O C}$ while the circuit is opened. Here, once more it is compulsory to set up a switch into the solar system; for the OV scheme the switch should be utilized to undo the circuit. While $I_{p v}=0$ no power is delivered by the solar system and accordingly no energy is produced.

Perturb and observe technique: A closer observation of the characteristics in Fig.2 (a) can explain the basic strategy behind the Perturb and Observe technique. An enlarge in PV voltage consequences in a raise in solar power output till a working point lies on the left region of the highest power point. In the same way if an enlarge in a solar voltage is consequential in a decline in solar power after that a working point lies in the right region of the MPP. The $\mathrm{P}$ and $\mathrm{O}$ technique uses this particular feature. The flow chart diagram of the $\mathrm{P}$ and $\mathrm{O}$ method is shown in Fig.2 (b) A DC voltage value across the PV is continuously perturbed and the PV Power is observed. The change in voltage is maintained in the same direction if a change in the PV voltage value is increasing the PV power, otherwise the dc link voltage will change in reverse direction. The process is continuously operational until MPP is achieved. A PV current also can be perturbed in order to get MPP instead a PV voltage. This perturbation in a PV voltage value or a current value is measured by changing the duty ratio of the power converter.

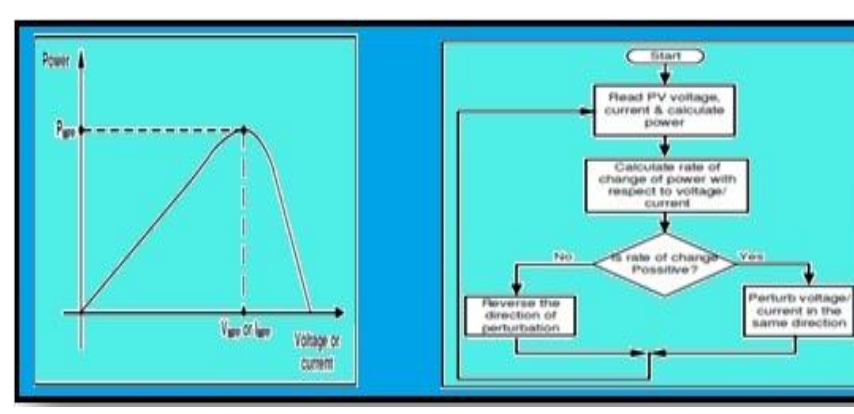

Fig. 2(a) Power against voltage or current characteristic 2(b) flow chart $P$ and $O$

The objective of a MPPT technique is to track the Vmpp at the every value of the irradiance and the so the maximum power output Pmpp can be injected into a power system grid. There are several temperature MPPT techniques available to achieve this namely, perturb and observe technique, incremental conductance method, partial short circuit current or open circuit voltage etc. The technique used here is incremental conductance method.

\section{(d) Incremental Conductance Meth}

The incremental conductance procedure continuously monitors the conductance value in order to achieve the MPP. It can be said that on MPP, rate of change of solar PV power $P_{P V}$ with respect to the PV voltage $I_{P V}$ is zero,

$$
\frac{d\left(P_{p v}\right)}{d_{P V}}=0
$$

The rate of change of PV power by way of PV voltage can be represented as;

$$
\begin{aligned}
& P_{p v}=V_{p v} \times I_{p v} \\
& \frac{d\left(P_{p v}\right)}{d_{P V}}=I_{p v}+V_{p v} \frac{d}{d V_{p v}}\left(I_{p v}\right)
\end{aligned}
$$

Hence the following expression can be written in the three regions of the PV characteristics. At the MPP, the following expression is true.

$$
\frac{\Delta I_{p v}}{\Delta V_{p v}}=-\frac{I_{p v}}{V_{p v}}
$$

The left region of MPP when the PV power rises with the boost in PV voltage, the following expression is true.

$$
\frac{\Delta I_{p v}}{\Delta V_{p v}}>-\frac{I_{p v}}{V_{p v}}
$$

The right side of MPP when the PV power decreases with the increase in

$\mathrm{PV}$ voltage, the following expression is true.

$$
\frac{\Delta I_{p v}}{\Delta V_{p v}}<-\frac{I_{p v}}{V_{p v}}
$$

Thus comparing the instantaneous conductance value, a reference voltage can be set for a PV in order to achieve PMPP using the expressions. The fractional open circuit voltage method makes use of the fact that the highest power point voltage ( $\left.V_{m p p}\right)$ and open- circuit voltage $\left(V_{O C}\right)$ have a linear relationship amongst them. The PV short circuit current ISC and current (IMPP) also have a linear correlation.

$$
\begin{aligned}
& \mathrm{VMPP}=\mathrm{K} 1 . \mathrm{VOC} \\
& \mathrm{IMPP}=\mathrm{K} 2 . \mathrm{ISC}
\end{aligned}
$$

The constants of proportionality $\mathrm{K} 1$ and $\mathrm{K} 2$ in above equation can be computed by an empirical determination of the $V_{O C}$ and $V_{M P P}$ at different temperature and irradiance values. Once these proportionality constants are calculated, during the operation of a PV, VOC can be measured by momentarily shutting down the power converter. Thus by using the values of VOC (or ISC) and K1 (or K2) the MPP values of VMPP (or IMPP) can be computed.

Flow chart of INC method is shown below 


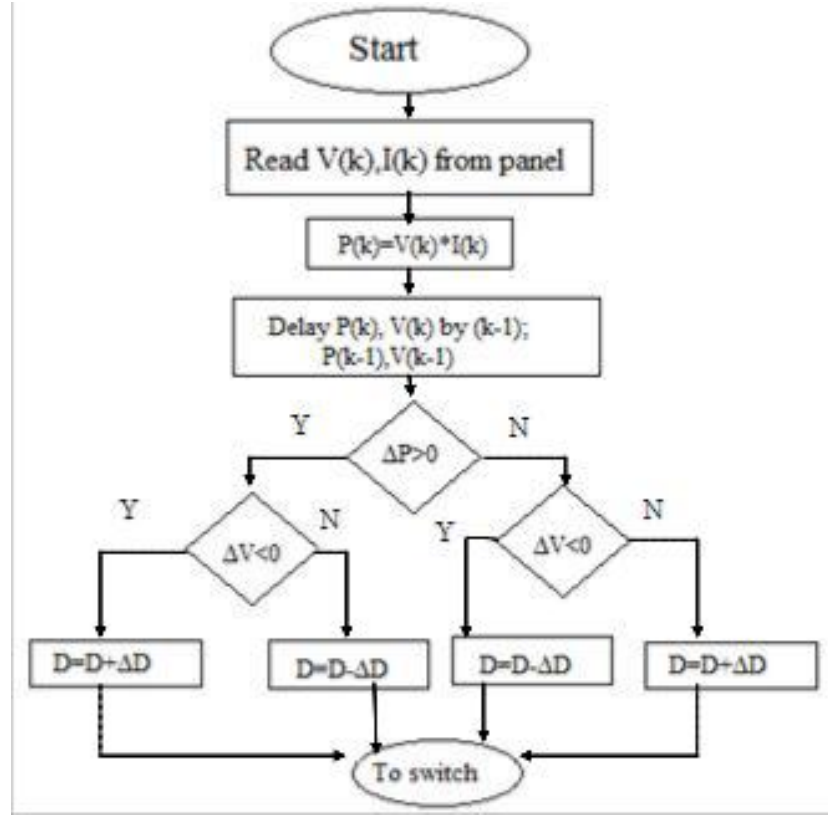

Fig. 3 (Flow Chart of INC Method)

\section{MPPT PROPOSED CONTROL CIRCUIT}

A schematic diagram of MPPT algorithm control circuit is shown in fig 4.In the boost converter, two level (upper and lower) are maintained for input capacitor voltage. The MPPT algorithm provides the upper level i.e. $\boldsymbol{V}_{\boldsymbol{P V} \boldsymbol{f}}^{\boldsymbol{R} \boldsymbol{f}}$.

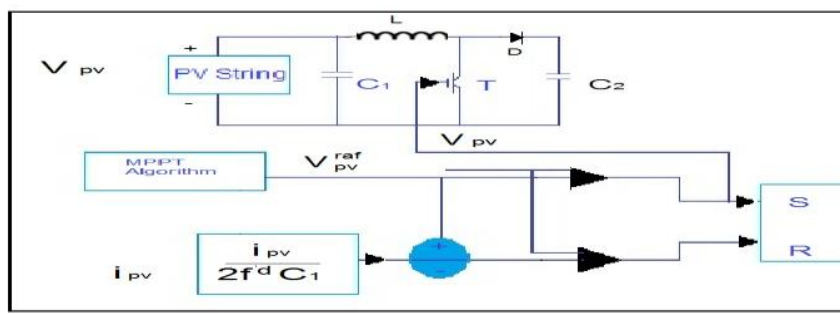

Fig. 4 (MPPT PROPOSED CONTROL CIRCUIT)

The lower level depends on worst conditions, i.e. voltage ripple and the switching frequency should not exceed definite values. The main switch is $\mathrm{ON}$ when the capacitor voltage exceeds $V_{P V}^{R e f}$ and the capacitor starts discharging. The switch is ON till capacitor voltage becomes equal to lower limit. The lower limit is not considered as a stable value to limit the switching frequency. The lower limit is calculated as given below.

$$
\begin{aligned}
& \Delta \boldsymbol{V}_{\boldsymbol{p} \boldsymbol{v}}=\frac{\boldsymbol{I}_{\boldsymbol{p} \boldsymbol{v}}}{\boldsymbol{2}_{\boldsymbol{1}_{\mathbf{1}} \boldsymbol{f}^{\boldsymbol{d}}}} \\
& \text { e.g. } C_{1}=1 \quad \mu \mathrm{F}, f^{d}=20 \mathrm{kHz}, i_{p v}^{\max }=4.5 \mathrm{~A},
\end{aligned}
$$

variation in solar voltage, $\Delta_{\mathrm{Vpv}}=5 \mathrm{~V}$. The above equation shows that there is correlation between the capacitor value and switching frequency. The control algorithm is implemented in boost converter to feed the voltage source inverter.

The boost converter topology has some compensation over the buck for MPPT application due to the same reasons. Foremost of all, the current in inductor is a large amount less than that of the buck converter. For the choice of the IGBT and driver, the current rated is lesser in boost converter than in the buck converter. As solar systems depend on the irradiance, at night, a current will flow back into solar system from the grid side, which may reason of extensive damage and leakage loss. The reverse current flow is prevented by using blocking diodes. The diode is used as the blocking diode to evade reverse current in the boost converter. By comparing the natural frequency, the boost converter presents improved dynamic characteristics over the buck converter. For all-purposes, it shows advantages in conditions of a smaller resonance and wider bandwidth due to the little input capacitance of the boost converter.

\section{RESULTS AND DISCUSSIONS}

This chapter proposed the incremental conductance controller with MPPT by means of boost converter to retain the stable output power of the load at the greatest point under two conditions (i) at unpredictable irradiances, and (ii) stable temperatures and a unpredictable temperatures\& stable irradiances. This controller was tested with MATLAB. The simulation consequence presented with incremental conductance controller shows that

* At unpredictable irradiances and stable temperatures when the irradiance increases, at the same time current is increased. Although, the Voltage, remained reasonably constant during the irradiance range.

* At unpredictable temperatures and stable irradiances when that temperature is lesser, the maximum power is higher and open-circuit voltage is also high. Although, a low temperature delivers slightly lower short circuit current.

* PV system involves less time ( less than $0.7 \mathrm{~ms}$ ) to attain the highest power.

* Improved power output and higher efficiency under normal and varying conditions.

* The system shows improved dynamic performance and steady state performance for grid connected solar PV system simultaneously.

* The effect of the incremental conductance with MPPT connected system on the power of load connected at standard conditions $(1000 \mathrm{~W} / \mathrm{m} 2$ and $25^{\circ} \mathrm{C}$ ) has been shown in fig. 5

* The effect of the incremental conductance with MPPT connected system on the power of load connected at standard conditions $(900 \mathrm{~W} / \mathrm{m} 2$ and 25 C )

simultation diagram of inc method has been shown in fig. 6

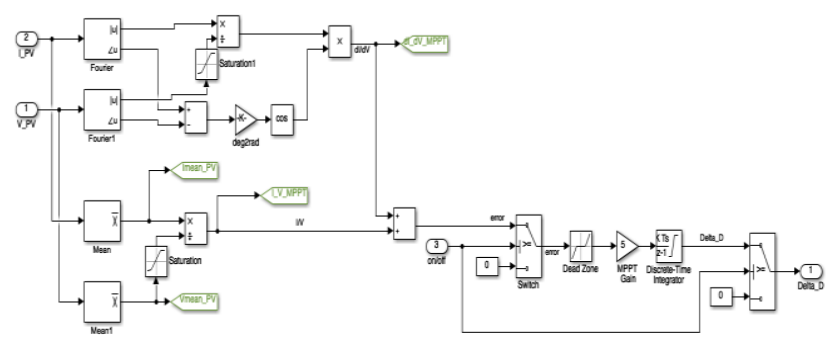

Fig. 5 (Simulation of INC method) 


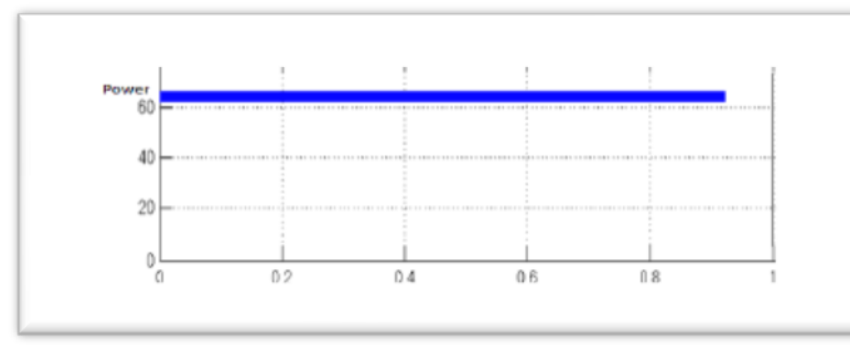

Fig. 6

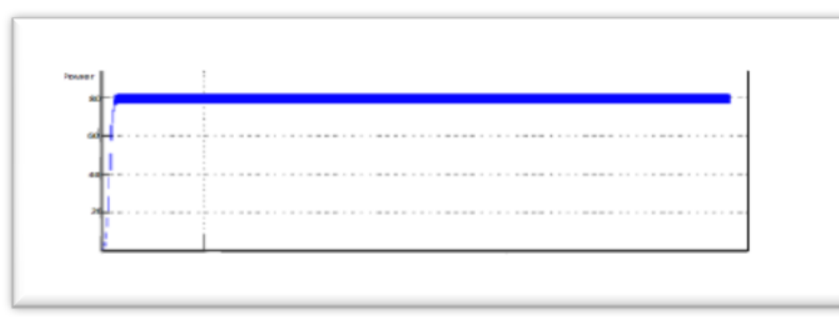

Fig. 7

The result shows that the incremental conductance based MPPT system requires less time $(0.7 \mathrm{~ms})$ to attain the maximum power. Thus the incremental conductance MPPT system is better in response and doesn't depend on knowing any parameter of PV panel. From the Simulation results we have also found that incremental conductance algorithms give better power output and higher efficiency under normal and varying conditions. Simulation results confirm that the presented method can effectively improve the dynamic performance and steady state performance simultaneously.

Whenever excess amount of energy is required solar power plant can be connected to grid. It results in overall increase in plant capacity thus increase both load factor and diversity factor of the system. By using MPPT control technique, always maximum power is taken from the PV array to result in increase of overall power of the system.

\section{REFERENCES}

[1] A. Chatterjee, A. Keyhani, and D. Kapoor, "Identification of Photovoltaic Source Models," Energy Conversion, IEEE Transactions on, vol. PP, pp. 1-7, 2011.Aalborg University, Denmark, 2012.accessed on November 10, 2012.

[2] A. Khalifa and E. El-Saadany,"Control of three-phase grid-connected photovoltaic arrays with open loop maximum power point tracking," Proceedings of IEEE Power and Energy Society General Meeting, pp. 1-8, 2011.

[3] A. Mansoor, et al, "Predicting the net harmonic currents produced by large numbers of distributed single-phase computer loads," Conference Record: IEEE PES Winter Power Conference, Jan. 1995, \#95 WM 260-0 PWRD.

[4] A. Yazdani and R. Iravani, "Voltage-sourced converters in power systems," John Wiley and Sons, 2010.

[5] A.K.Zairian, M. Karimi Ghartemani. "On the equivalence of three independently developed phase-locked loops,"
IEEE Trans. on Automation Control, Vol. 50, No.12, pp. 2021-2027, 2005.

[6] A. Ellis, R. Nelson, E. VonEngeln, R. Walling, J. MacDowell, L. Casey, E. Seymour, W. Peter, C. Barker, B. Kirby, and J. Williams, "Review of existing reactive power requirements for variable generation," IEEE Power and Energy Society General Meeting, 2012, San Diego, USA, pp. 1-7, Jul. 2012.

[7] A. Hoke, R. Butler, J. Ham brick and B. Kropotkin, "Steady-State Analysis of Maximum Photovoltaic Penetration Levels on Typical Distribution Feeders," IEEE Transactions on Sustainable Energy, vol. 4, no. 2, pp. 350 - 357, 2012.

[8] A. B. Gregene, H. R. Camenzind. "Frequency-selective integrated circuits using phase-lock techniques". IEEE Journal of Solid-State Circuits, Vol.4, No.4, pp. 216-225, 1969.

[9] B. Lindgren, "A Power Converter for Photovoltaic Applications," Licentiate of Engineering Degree, Department of Electric Power Engineering, Chalmers University of Technology Goteborg, Sweden, 2000.

[10] B.Verhoeven, "Utility aspects of grid connected photovoltaic power systems," International Energy Agency Implementing Agreement on Photovoltaic Power Systems, Report IEA PVPS T5-01, 1998.

[11] BP Solar, PV System Specification- Solar Skin PV Norway Trondheim, Doc . 10068650 rev, 2. BP Solar Limited, March 2000.

[12] C.R. Nave, "The P-N Junction," Physics World, 2012. http://hyperphysics.phy-

astr.gsu.edu/hbase/solids/pnjun.html\#c3.[Accessed 20 September 2014].

[13] C.Wang, "Modelling and Control of Hybrid Wind/Photovoltaic/Fuel cell Distributed Generation Systems," PhD Dissertation, Montana State University, Bozeman, 2006.

[14] C.S.T. Huan-Liang Tsai, and Yi-Jie Su, "Development of Generalized Photovoltaic Model Using MATLAB/SIMULINK," In the World Congress on Engineering and Computer Science 2008, San Francisco, USA, 2008.

[15] Clean Energy Council, Tech Info Energy Efficient and Renewable

EnergyBulletin.September2006.UpdatedNovember2009. $\mathrm{http}: / / \mathrm{www}$. solaraccreditation.com.au/installerr sources'/tech info.html. accessed on November 10,2012

[16] D. C. Martins, "Analysis of a three-phase grid-connected PV power system using a modified dual-stage inverter," International Scholarly Research Notices (ISRN) Renewable Energy, vol. 2013, pp. 1-18, 2013.

[17] D. E. Rice, "Adjustable speed drive and power rectifier harmonic - their effect on power systems components," IEEE Trans. on Ind. Appl., Vol. IA-22, No. 1, Jan./Feb. 1986, 161. 